\title{
Reduction of crystalline iron(III) oxyhydroxides using hydroquinone: Influence of phase and particle size
}

\author{
Amy J. Anschutz and R. Lee Penn ${ }^{\text {a) }}$ \\ Department of Chemistry, University of Minnesota, Minneapolis, Minnesota 55455
}

(Received 7 January 2005; accepted 25 July 2005; published 9 September 2005)

\begin{abstract}
Iron oxides and oxyhydroxides are common and important materials in the environment, and they strongly impact the biogeochemical cycle of iron and other species at the Earth's surface. These materials commonly occur as nanoparticles in the $3-10 \mathrm{~nm}$ size range. This paper presents quantitative results demonstrating that iron oxide reactivity is particle size dependent. The rate and extent of the reductive dissolution of iron oxyhydroxide nanoparticles by hydroquinone in batch experiments were measured as a function of particle identity, particle loading, and hydroquinone concentration. Rates were normalized to surface areas determined by both transmission electron microscopy and Braunauer-Emmett-Teller surface. Results show that surface-area-normalized rates of reductive dissolution are fastest (by as much as 100 times) in experiments using six-line ferrihydrite versus goethite. Furthermore, the surface-area-normalized rates for $4 \mathrm{~nm}$ ferrihydrite nanoparticles are up to 20 times faster than the rates for $6 \mathrm{~nm}$ ferrihydrite nanoparticles, and the surface-area-normalized rates for $5 \times 64 \mathrm{~nm}$ goethite nanoparticles are up to two times faster than the rates for $22 \times 367 \mathrm{~nm}$ goethite nanoparticles. (C) 2005 American Institute of Physics. [DOI: 10.1063/1.2037887]
\end{abstract}

\section{INTRODUCTION}

Iron oxide and oxyhydroxides, hereafter referred to as iron oxides, often occur as nanoparticles in the $3-10 \mathrm{~nm}$ size range and are found in diverse environments, such as in weathering rinds of iron-bearing minerals or in lakes, streams, aquifers, and acid mine drainage. ${ }^{1,2}$ These materials can be formed and transformed by a variety of redox and nonredox processes, which can be driven both abiotically and biotically. ${ }^{3,4}$ For example, Thiobacillus ferrooxidans has been shown to catalyze the oxidation of Fe(II), ${ }^{5}$ whereas $S h$ ewanella species have been shown to reductively dissolve

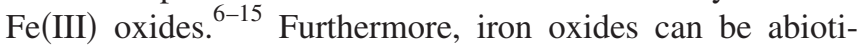
cally formed through chemical weathering of iron-bearing minerals or when aqueous fluids containing high concentrations of dissolved $\mathrm{Fe}$ (II) encounter fluids rich in dissolved oxygen. ${ }^{2}$ Such reactions can result in phase changes through precipitation, dissolution, and solid-state phase transformations. ${ }^{6,12,14,16}$ These are often key elements of the processes governing the transport and fate of naturally occurring and anthropogenic chemical species, such as nitroaromatics and arsenic species. ${ }^{1,2,17-19}$

Previous work has examined size-dependent reactivity of nanoscale materials in catalysis, ${ }^{20,21}$ adsorption, ${ }^{2-24}$ and biotic dissolution. ${ }^{8,13}$ Furthermore, many researchers have attempted to systematically examine the relative reactivity of iron oxide particles (e.g., Refs. 3, 6, 7, 9, 13, and 25-31, and references contained therein). Many such studies attempt to link particle size with reactivity but lack a holistic and consistent characterization of the solid materials used. Findings are often inconsistent, and differences observed are often small and difficult to explain. Finally, recent work has addressed whether reactivity trends are consistent between abi-

\footnotetext{
${ }^{a)}$ Author to whom correspondence should be addressed; electronic mail: penn@chem.umn.edu
}

otic and biotic experiments using iron oxide particles of different phase and size. ${ }^{7,9}$ Much of this work suggests a particle size effect in the reactivity of the iron oxides. Comparisons between these distinct types of work could be substantially strengthened by the use of a common set of materials, especially in the case of experiments using a broad range of redox agents and microorganisms. In such a way, the idea of universal reactivity (e.g., whether similar trends are observed for abiotic and biotic reactions involving the same particles) can be tested, and we are developing a wellcharacterized library of procedures, characterization results, and even some solid materials that can be used by many different research groups in order to make meaningful comparisons between varieties of experiments (including both abiotic and biotic experiments) possible.

This paper presents quantitative results demonstrating that abiotic iron oxide reactivity is particle size dependent. Specifically, this paper examines the abiotic reduction of two types of well-characterized ferrihydrite $\left(\mathrm{Fe}_{5} \mathrm{HO}_{8} \cdot 4 \mathrm{H}_{2} \mathrm{O}\right)^{3}$ and goethite $(\alpha-\mathrm{FeOOH})$ nanoparticles using hydroquinone as the reducing agent. Hydroquinone was selected because many of the biotic mechanisms involving redox of iron oxides use quinones as electron shuttles. ${ }^{11,12,32-36}$ Also, quinone functional groups have been found in natural humic substances and can be generated biotically through the degradation of lignins, among other compounds. ${ }^{37,38}$ A number of researchers have studied the reduction of iron oxides by quinones and results show they can effectively be used to quantitatively evaluate the reactivity of these particles. ${ }^{28,39-42}$

\section{MATERIALS AND METHODS}

\section{A. Synthesis of six-line ferrihydrite $-4 \mathrm{~nm}$ dots (4nm-6LF)}

The synthesis method was adapted from Burleson and Penn. ${ }^{43}$ Using a peristaltic pump at a rate of $4.58 \mathrm{~mL} / \mathrm{min}$, 
1.0 $\mathrm{L}$ of $0.4799 \mathrm{M} \mathrm{NaHCO}_{3}$ (Fisher, ACS grade) was added dropwise to a continuously stirred $1.0 \mathrm{~L}$ solution of $0.4000 \mathrm{M} \mathrm{Fe}\left(\mathrm{NO}_{3}\right)_{3} \cdot 9 \mathrm{H}_{2} \mathrm{O}$ (Fisher, ACS grade). During the transfer, the solution changed from bright orange to dark brownish red with no visible precipitate. The suspension was separated into $250 \mathrm{~mL}$ Nalgene bottles and microwaved one at a time until boiling occurred, shaking every $40 \mathrm{~s}$ (most boiled after $120 \mathrm{~s}$ ). Immediately after heating, each suspension was plunged into an ice bath until it reached $\sim 20{ }^{\circ} \mathrm{C}$. In order to remove the counter ions present from the synthesis, the cooled suspensions were placed into dialysis bags $(\mathrm{MWCO}=2000)$, which were placed in Milli-Q® $\mathrm{H}_{2} \mathrm{O}$. The water was changed three times per day for three days. The resulting suspensions were placed in a number of weigh boats, covered, and placed in a fume hood to dry. The justification for drying the particles is that previous results have shown that the six-line ferrihydrite nanoparticles prepared using this method are not stable in aqueous suspension because they grow by oriented aggregation accompanied by phase transformation to goethite in a relatively short period of time, even at room temperature (i.e., within a few weeks). ${ }^{43}$ Using a mortar and pestle, the dry, dark reddish brown particles were ground into a fine powder and stored in a glass vial.

\section{B. Synthesis of six-line Ferrihydrite- $6 \mathrm{~nm}$ dots (6nm-6LF)}

The synthesis method was adapted from Schwertmann and Cornell. ${ }^{44}$ With stirring, $20 \mathrm{~g}$ of solid $\mathrm{Fe}\left(\mathrm{NO}_{3}\right)_{3} \cdot 9 \mathrm{H}_{2} \mathrm{O}$ was added to $2.0 \mathrm{~L}$ of Milli-Q $\mathrm{H}_{2} \mathrm{O}$ at $75^{\circ} \mathrm{C}$. The solution temperature was maintained at $75{ }^{\circ} \mathrm{C}$ for $12 \mathrm{~min}$. After heating, the solution was plunged into an ice bath until it reached $\sim 20{ }^{\circ} \mathrm{C}(\sim 30 \mathrm{~min})$. The cooled suspension was dialyzed, dried, and ground as described earlier.

\section{Synthesis of nanorods of goethite $(\alpha-\mathrm{FeOOH})$}

The synthesis of the nanorods began by using the $4 \mathrm{~nm}-6 \mathrm{LF}$ synthesis procedure (Sec. II A). After dialysis, the $\mathrm{pH}$ of the ferrihydrite suspension was quickly adjusted to 12 using $5 \mathrm{M} \mathrm{NaOH}$ (Fisher, ACS grade). A deep maroon suspension formed. The suspension was heated at $90^{\circ} \mathrm{C}$ for $24 \mathrm{~h}$, after which a deep orange precipitate had settled to the bottom quarter of the bottle. The supernatant was discarded, and the remaining suspension was placed into dialysis bags, which were placed in Milli-Q $\mathrm{H}_{2} \mathrm{O}$. The water was changed three times per day for three days. The resulting suspension was dried and ground as described above.

\section{Synthesis of microrods of goethite $(\alpha-\mathrm{FeOOH})$}

The synthesis method was adapted from Schwertmann and Cornell. ${ }^{44}$ With stirring, $40 \mathrm{~g}$ of $\mathrm{Fe}\left(\mathrm{NO}_{3}\right)_{3} \cdot 9 \mathrm{H}_{2} \mathrm{O}$ was added to $900 \mathrm{~mL}$ of Milli-Q $\mathrm{H}_{2} \mathrm{O}$. While stirring, the $\mathrm{pH}$ was adjusted to 12 using $5 \mathrm{M} \mathrm{NaOH}$. A deep maroon suspension formed. The suspension was heated in an oven at $90{ }^{\circ} \mathrm{C}$ for one week, after which a yellow-orange precipitate had settled to the bottom quarter of the bottle. The supernatant was discarded, and the remaining suspension was placed into dialysis bags, which were placed in Milli-Q $\mathrm{H}_{2} \mathrm{O}$. The water was changed three times per day for three days. The resulting suspension was dialyzed, dried, and ground as described earlier.

\section{E. Reduction reactions}

All preparations and reactions were performed in a catalytically maintained anaerobic environment $\left(\sim 3 \% \mathrm{H}_{2}\right.$ in $\mathrm{N}_{2}$, vinyl anaerobic chamber, Coy Laboratory Products Inc., $\mathrm{O}_{2}$ $<100 \mathrm{ppm}$, as measured by an oxygen/hydrogen gas analyzer). Suspensions were stirred using Teflon ${ }^{\mathrm{TM}_{-}}$-coated stir bars, and all reaction bottles were covered with aluminum foil to prevent exposure to light.

Known masses $(75,50,25$, or $12.5 \mathrm{mg})$ of particles were placed in clean, $30 \mathrm{~mL}$ Nalgene bottles containing $5.0 \mathrm{~mL}$ of $40 \mathrm{mM}, \mathrm{pH} 3.75$ acetate buffer [prepared using glacial acetic acid (Mallinckrodt, ACS grade) and $\mathrm{NaOH}$ ] that had been purged with $\mathrm{N}_{2}$ gas for at least $20 \mathrm{~min}$. The suspensions were capped, removed from the anaerobic chamber, and sonicated for $10 \mathrm{~min}$. After returning the bottles to the anaerobic chamber and stirring overnight, the appropriate volume of acetate buffer (to bring the final reaction volume to $25.0 \mathrm{~mL}$ ) and $10 \mathrm{mM}$ hydroquinone $\left(\mathrm{QH}_{2}\right.$, Sigma, 99\%) stock solution were added. The samples were stirred continuously throughout the experiment. At desired time intervals, $1.0 \mathrm{~mL}$ aliquots were removed and filtered using a $0.2 \mu \mathrm{m}$ Pall nylon filter membrane. The concentration of $p$-benzoquinone $(\mathrm{Q})$ at time $t,[\mathrm{Q}]_{t}$, was immediately quantified $(<1 \mathrm{~min})$ via high performance liquid chromatography (HPLC). Stop time was recorded as the time of filtering. The solid concentration was assumed to be constant since no settling or clumping of the particles was observed during sampling.

Blank samples containing only $\mathrm{QH}_{2}$ in acetate buffer were used to account for the spontaneous oxidation of $\mathrm{QH}_{2}$ to $\mathrm{Q}$.

\section{F. HPLC method}

Samples were quantified using an Agilent Technologies 1100 Series HPLC equipped with a Zorbax ${ }^{\circledR} \mathrm{C}_{18}$ Stable Bond column. The flow rate was $0.75 \mathrm{~mL} / \mathrm{min}$, and the mobile phase consisted of $65 \mathrm{vol} \% 40 \mathrm{mM}, \mathrm{pH} 3.75$ acetate buffer, and 35 vol \% acetonitrile (Pharmco, HPLC grade). The detecting wavelength was $235 \mathrm{~nm}$. The injection volume was $10 \mu \mathrm{L}$. Using this method, the retention time of $\mathrm{QH}_{2}$ was $2.4 \mathrm{~min}$, and the retention time of $\mathrm{Q}$ was $3.4 \mathrm{~min}$. An eight-point calibration curve from 0 to $1 \times 10^{-2} \mathrm{M} \mathrm{QH}_{2}$ and an eight-point calibration curve from $0 \mathrm{M}$ to $1 \times 10^{-3} \mathrm{M} \mathrm{Q}$ (Acros, 99+\%) were used.

\section{G. Ferrozine assay}

Aqueous [Fe(II)] was determined using an adaptation of the Ferrozine assay ${ }^{45}$ for a subset of experiments in order to confirm that the reaction proceeded via reductive dissolution and to verify the stoichiometry of the reaction for each particle type. Immediately after HPLC analysis, $0.80 \mathrm{~mL}$ of the filtered sample was combined with $0.25 \mathrm{~mL}$ of $5 \mathrm{~g} / \mathrm{L}$ Ferrozine (Acros, 99.9\%) and $3.25 \mathrm{~mL} 40 \mathrm{mM}, \mathrm{pH} 3.75$ acetate buffer. Absorbance at $562 \mathrm{~nm}$ was measured using a Spectronic 20D+ visible spectrophotometer. A standard Fer- 


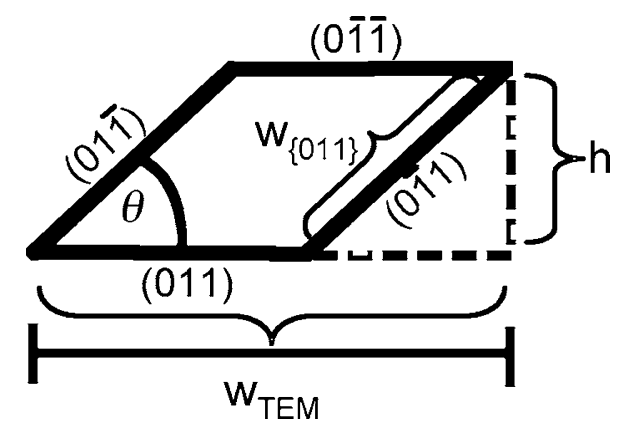

FIG. 1. Schematic cross section of a goethite rod, in which $w_{\text {TEM }}$ is the measured width using TEM, $w_{\{011\}}$ is the width of a $\{011\}$ facet, $h$ is the height, and $\theta$ is the angle between the $\{011\}$ faces $\left(46.70^{\circ}\right)$.

rozine/acetate buffer solution was used as a blank. An eightpoint calibration curve from $0 \mathrm{M}$ to $1 \times 10^{-4} \mathrm{M} \mathrm{FeCl}_{2} \cdot 4 \mathrm{H}_{2} \mathrm{O}$ (Fisher, ACS grade) was used. Blanks containing particles in buffer (no reductant) were also tested. For at least one sample of each particle type, the amount of Fe(II) adsorption onto the nanoparticles was determined by difference between the total $\mathrm{Fe}(\mathrm{II})$ equivalents in solution and the benzoquinone equivalents produced.

\section{H. Materials characterization}

Particles were characterized by three different methods: $\mathrm{X}$-ray diffraction (XRD), transmission electron microscopy (TEM), and Brunauer-Emmett-Teller surface area analysis (BET). ${ }^{46}$

XRD was performed using a PANalytical X'Pert Pro theta-theta diffractometer equipped with a Co anode and an $\mathrm{X}^{\prime}$ Celerator detector. Data collection ranges and collection times were $10^{\circ}$ to $90^{\circ} 2 \theta$ and $120 \mathrm{~min}$, respectively, for ferrihydrite samples and $15^{\circ}$ to $90^{\circ} 2 \theta$ and $30 \mathrm{~min}$ for goethite samples. The diffraction patterns were compared to PDF (powder diffraction file) No. 29-0712 (six-line ferrihydrite) and PDF No. 29-0713 (goethite).

TEM samples were prepared by diluting and sonicating the dried samples and then placing one drop onto a $3 \mathrm{~mm}$ holey carbon coated $\mathrm{Cu}$ grid (SPI Supplies). Samples were characterized using a Tecnai T12 TEM equipped with a Gatan CCD camera. The specific surface area for each sample of nanoparticles was measured by two methods. First, specific surface area by TEM $\left(\mathrm{SA}_{\mathrm{TEM}}\right)$ was estimated by using particle size and size distribution data from a minimum of 500 particles. Ferrihydrite nanoparticles were modeled as spheres, and the specific surface area was calculated for each particle measured using the density $\left(3.96 \mathrm{~g} / \mathrm{cm}^{3}\right)$ from Cornell and Schwertmann. ${ }^{3}$ Then, an average specific surface area was calculated. Goethite nanoparticles were modeled as rhomboidal prisms bounded by $\{011\}$, and a schematic of the cross section of the assumed morphology is shown in Fig. 1. The TEM-measured width $\left(w_{\mathrm{TEM}}\right)$ was converted to the width of the 011-type faces $\left(w_{\{011\}}\right)$ to account for the preferred orientation of particles on the grid, and a specific surface area was calculated for each particle measured using the density of goethite $\left(4.26 \mathrm{~g} / \mathrm{cm}^{3}\right)$ from Cornell and Schwertmann, ${ }^{3} w_{\{011\}}, L_{\mathrm{TEM}}$, and $\theta$ (the angle between the 011-type faces). The assumed morphology is consistent with

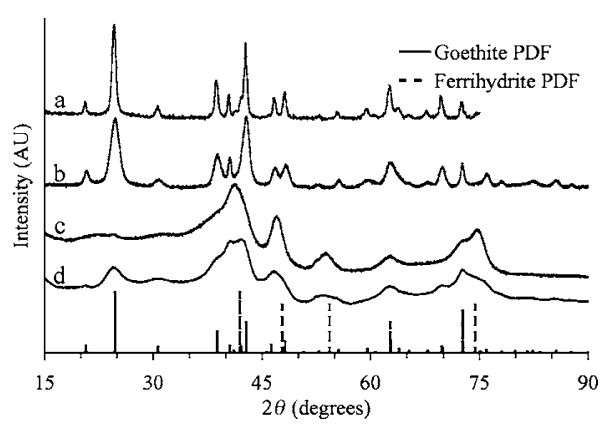

FIG. 2. XRD patterns for (a) microrods, (b) nanorods, (c) $6 \mathrm{~nm}-6 \mathrm{LF}$, and (d) 4 nm-6LF. Goethite (No. 29-0713, solid lines) and ferrihydrite (No. 290712, dashed lines) PDFs have been included for comparison.

atomic force microscopy images (unpublished data) and with the TEM images, which show unequal projected facet lengths at the goethite crystallite tips (see Sec. III A). An average specific surface area was then calculated. Second, specific surface area $\left(\mathrm{SA}_{\mathrm{BET}}\right)$ was estimated using elevenpoint adsorption data from the linear portion of $N_{2}$ adsorption isotherms ${ }^{47}$ in the relative pressure range 0.05-0.2 using BET theory. Prior to BET analysis, samples were degassed for $12 \mathrm{~h}$ at room temperature $\left(24-34^{\circ} \mathrm{C}\right)$.

\section{RESULTS AND DISCUSSION}

\section{A. Characterization}

Figure 2 shows XRD patterns for each particle type. The patterns clearly show that both the microrods [Fig. 2(a)] and the nanorods [Fig. 2(b)] are goethite with no peaks consistent with six-line ferrihydrite or hematite observed. The pattern [Fig. 2(c)] for $6 \mathrm{~nm}-6 \mathrm{LF}$ particles clearly shows that this material is six-line ferrihydrite, and no peaks consistent with goethite or hematite were observed. In contrast, the pattern for the $4 \mathrm{~nm}$-6LF particles shows that the material is predominantly six-line ferrihydrite with a small amount of goethite. In order to estimate the goethite to ferrihydrite ratio, an XRD pattern from a mixture of known goethite and ferrihydrite masses was collected, and by comparing to Fig. 2(d), the goethite content of $4 \mathrm{~nm}-6 \mathrm{LF}$ was estimated to be approximately $10 \mathrm{wt} \%$. In addition, by quantifying the full width at half maximum of the goethite $\{011\}$ peak and using the Scherrer equation, ${ }^{48}$ an average goethite size of $3.5 \mathrm{~nm}$ was calculated.

The average specific surface areas $\left(\mathrm{SA}_{\mathrm{BET}}\right.$ and $\left.\mathrm{SA}_{\mathrm{TEM}}\right)$ for each particle type, along with $w_{\mathrm{TEM}}$ and $L_{\mathrm{TEM}}$, are shown in Table I, and representative TEM images are shown in Fig. 3 . In the cases of $6 \mathrm{~nm}-6 \mathrm{LF}$, nanorods, and microrods, the $\mathrm{SA}_{\mathrm{BET}}$ and $\mathrm{SA}_{\mathrm{TEM}}$ values are similar, although the former are consistently and slightly lower than the latter. This probably reflects a small amount of aggregation due to drying. However, $\mathrm{SA}_{\mathrm{BET}}$ for $4 \mathrm{~nm}-6 \mathrm{LF}$ is inexplicably high. Thus, surface-area-normalized rate constants calculated using $\mathrm{SA}_{\text {TEM }}$ were deemed most appropriate for comparisons between the ferrihydrite nanoparticles. 
TABLE I. Surface areas ( \pm standard deviation) for iron oxyhydroxide particles used. $\mathrm{SA}_{\mathrm{BET}}$ denotes surface area determined by the BET method, and $\mathrm{SA}_{\text {TEM }}$ denotes surface area determined from particle size data obtained from TEM images (see the text).

\begin{tabular}{cccccc}
\hline \hline Particle ID & Phase & $\begin{array}{c}\mathrm{SA}_{\mathrm{BET}} \\
\left(\mathrm{m}^{2} / \mathrm{g}\right)\end{array}$ & $\begin{array}{c}\mathrm{SA}_{\mathrm{TEM}} \\
\left(\mathrm{m}^{2} / \mathrm{g}\right)\end{array}$ & $\begin{array}{c}\mathrm{Width}^{\mathrm{a}} \\
(\mathrm{nm})\end{array}$ & $\begin{array}{c}L_{\mathrm{TEM}} \\
(\mathrm{nm})\end{array}$ \\
\hline $4 \mathrm{~nm}-6 \mathrm{LF}$ & Fh & $1565 \pm 27$ & $409 \pm 74$ & $4.0 \pm 0.2$ & $\mathrm{n} / \mathrm{a}$ \\
$6 \mathrm{~nm}-6 \mathrm{LF}$ & Fh & $234.9 \pm 0.5$ & $271 \pm 49$ & $5.9 \pm 0.3$ & $\mathrm{n} / \mathrm{a}$ \\
Nanorods & Gt & $136.8 \pm 0.5$ & $210 \pm 19$ & $5.3 \pm 0.3$ & $64 \pm 3$ \\
Microrods & Gt & $38.19 \pm 0.19$ & $53 \pm 5$ & $22 \pm 1.1$ & $367 \pm 18$ \\
\hline \hline
\end{tabular}

$\overline{\bar{a}}$ For ferrihydrite (Fh), width is diameter of particle, and for goethite $(\mathrm{Gt})$, width is $w_{\{011\}}$ (see Fig. 1)

\section{B. Kinetics}

The anticipated half reactions and overall reaction of ferrihydrite [Eq. (1)] or goethite [Eq. (2)] with hydroquinone $\left(\mathrm{QH}_{2}\right)$ can be written as

$$
\begin{aligned}
& 2 \mathrm{Fe}_{5} \mathrm{HO}_{8} \cdot 4 \mathrm{H}_{2} \mathrm{O}(\mathrm{s})+10 \mathrm{e}^{-}+30 \mathrm{H}^{+}(\mathrm{aq}) \rightarrow 10 \mathrm{Fe}^{2+}(\mathrm{aq}) \\
& \quad+24 \mathrm{H}_{2} \mathrm{O}(1) \\
& 5 \mathrm{QH}_{2}(\mathrm{aq}) \rightarrow 5 \mathrm{Q}(\mathrm{aq})+10 \mathrm{e}^{-}+10 \mathrm{H}^{+}(\mathrm{aq}) \\
& 2 \mathrm{Fe}_{5} \mathrm{HO}_{8} \cdot 4 \mathrm{H}_{2} \mathrm{O}(\mathrm{s})+5 \mathrm{QH}_{2}(\mathrm{aq})+20 \mathrm{H}^{+}(\mathrm{aq}) \rightarrow 5 \mathrm{Q}(\mathrm{aq}) \\
& \quad+10 \mathrm{Fe}^{2+}(\mathrm{aq})+24 \mathrm{H}_{2} \mathrm{O}(1) \\
& \left.10 \alpha-\mathrm{FeOOH}^{\mathrm{s}}\right)+10 \mathrm{e}^{-}+30 \mathrm{H}^{+}(\mathrm{aq}) \rightarrow 10 \mathrm{Fe}^{2+}(\mathrm{aq}) \\
& \quad+20 \mathrm{H}_{2} \mathrm{O}(1), \\
& 5 \mathrm{QH}_{2}(\mathrm{aq}) \rightarrow 5 \mathrm{Q}(\mathrm{aq})+10 \mathrm{e}^{-}+10 \mathrm{H}^{+}(\mathrm{aq}) \\
& 10 \alpha-\mathrm{FeOOH}(\mathrm{s})+5 \mathrm{QH}_{2}(\mathrm{aq})+20 \mathrm{H}^{+}(\mathrm{aq}) \rightarrow 5 \mathrm{Q}(\mathrm{aq}) \\
& \quad+10 \mathrm{Fe}^{2+}(\mathrm{aq})+20 \mathrm{H}_{2} \mathrm{O}(1)
\end{aligned}
$$

The concentrations (in equivalents/L) of $\mathrm{Q}$ versus time for experiments using $2.0 \mathrm{~g} / \mathrm{L}$ of $4 \mathrm{~nm}-6 \mathrm{LF}$ particles with

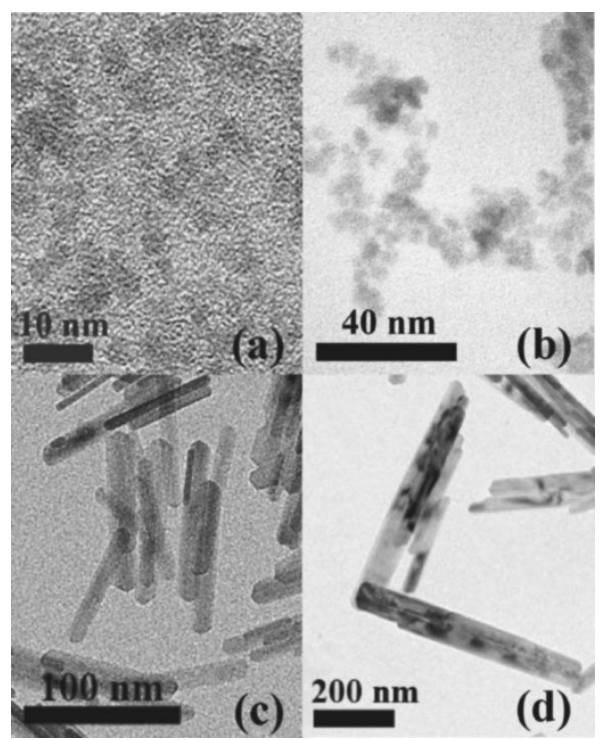

FIG. 3. TEM images of iron oxyhydroxide nanoparticles. (a) $4 \mathrm{~nm}-6 \mathrm{LF}$ (Fh), (b) $6 \mathrm{~nm}-6 \mathrm{LF}$ (Fh), (c) nanorods (Gt), and (d) microrods (Gt).
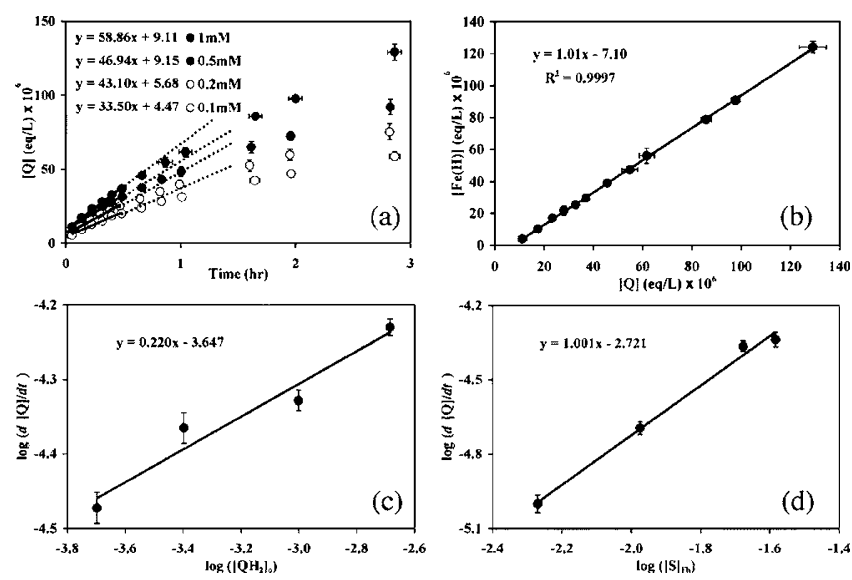

FIG. 4. Semiquantitative comparison using the method of initial rates: (a) concentration of $\mathrm{Q}$ (in equivalents/L) vs time for experiments using $2.0 \mathrm{~g} / \mathrm{L}$ $4 \mathrm{~nm}-6 \mathrm{LF}$ and $1.0 \mathrm{mM}$ (black dots), $0.50 \mathrm{mM}$ (dark gray dots), $0.20 \mathrm{mM}$ (light gray dots), and $0.10 \mathrm{mM}$ (white dots) $\mathrm{QH}_{2}$. Solid lines represent the linear regression, which have been extended using a dotted line for clarity. (b) Concentration of $\mathrm{Fe}(\mathrm{II})$ vs $\mathrm{Q}$ (in equivalents/L) for $2.0 \mathrm{~g} / \mathrm{L} 4 \mathrm{mn}-6 \mathrm{LF}$ and $1.0 \mathrm{mM} \mathrm{QH}_{2}$. In both (a) and (b), equations listed were generated by linear least-squares regression analysis of the linear portion of the data (solid lines). The $y$-error bars represent the standard deviation in analyte concentration, and the $x$ bars represent the standard deviation in sampling times for three trials. (c) Log-log plot of $d[\mathrm{Q}] / d t$ vs $\left[\mathrm{QH}_{2}\right]_{0}$. The slope is the empirical reaction order $(m)$ with respect to $\mathrm{QH}_{2}$ [see Eq. (3)]. (d) Log-log plot of $d[\mathrm{Q}] / d t$ vs $[\mathrm{S}]_{\mathrm{Fh}}$. The slope is the empirical reaction order $(n)$ with respect to the surface [see Eq. (3)]. In (c) and (d), equations listed were generated by linear least-squares regression analysis of the data (solid lines)

1.0, 0.50, 0.20, and $0.10 \mathrm{mM}$ initial $\mathrm{QH}_{2}$ are shown in Fig. 4(a). Figure 4(b) shows an example of [Fe(II)] versus [Q] (in equivalents/L) for $2.0 \mathrm{~g} / \mathrm{L}$ of $4 \mathrm{~nm}-6 \mathrm{LF}$ particles with $1.0 \mathrm{mM} \mathrm{QH} \mathrm{QH}_{2}$ confirms the expected reaction stoichiometry. Conversion of concentration to equivalents was based on the number of electrons transferred from $\mathrm{QH}_{2}$ to $\mathrm{Fe}$ (III) and reflects the 2:1 $\mathrm{Fe}(\mathrm{II}): \mathrm{Q}$ reaction stoichiometry [Eqs. (1) and (2)]. NMR confirms $\mathrm{QH}_{2}$ and $\mathrm{Q}$ as the only organic products of the reactions (results not shown). $\mathrm{QH}_{2}$ blanks showed rates of oxidation to $\mathrm{Q}$ two orders of magnitude slower than the slowest observed rate of reaction with oxide (results not shown). Dissolved Fe(II) was not observed in any particle blanks (results not shown). Previous work shows that Fe(II) adsorbs onto $\mathrm{Fe}(\mathrm{III})$ oxide surfaces, ${ }^{49}$ and based on that work, less than $10 \%$ of the total $\mathrm{Fe}(\mathrm{II})$ was expected to adsorb onto the nanoparticles. In all cases, results were consistent with that expectation.

For semiquantitative comparisons between different phases, initial rates were computed by fitting the linear portion [solid lines shown in Fig. 4(a)] of the graph to a least squares regression following the method of initial rates. ${ }^{50}$ Rate constants and reaction orders with respect to both $\mathrm{QH}_{2}$ and the reactive surface sites can be found using Eq. (3) (adapted from the method used by Stack et al. ${ }^{40}$ )

$$
d[\mathrm{Q}] / d t=r=k\left[\mathrm{QH}_{2}\right]^{m}[\mathrm{~S}]^{n},
$$

where $r$ is the rate of formation of $\mathrm{Q}, k$ is the rate constant, $\left[\mathrm{QH}_{2}\right]$ is the initial concentration of $\mathrm{QH}_{2}$ used, $m$ is the reaction order with respect to $\mathrm{QH}_{2}$, [S] is the initial concentration of reactive surface sites, which is assumed to be proportional to the total oxide concentration at time zero, and $n$ 
TABLE II. Reaction orders for $\mathrm{QH}_{2}(m)$ and surface $(n)$ and rate constants $(k)$ for semiquantitative comparison between each particle type by the method of initial rates. Errors reported are standard errors. $\mathrm{SA}_{\mathrm{TEM}}$ normalized rate constant is denoted by $k_{\mathrm{TEM}}$, and $\mathrm{SA}_{\mathrm{BET}}$ normalized rate constant is denoted by $k_{\mathrm{BET}}$.

\begin{tabular}{cccccc}
\hline \hline Particle ID & $m$ & $n$ & $k \times 10^{4}\left(\mathrm{~h}^{-1}\right)$ & $\begin{array}{c}k_{\mathrm{TEM}} \times 10^{5} \\
\left(\mathrm{~h}^{-1} \mathrm{~m}^{-2}\right)\end{array}$ & $\begin{array}{c}k_{\mathrm{BET}} \times 10^{5} \\
\left(\mathrm{~h}^{-1} \mathrm{~m}^{-2}\right)\end{array}$ \\
\hline $4 \mathrm{~nm}-6 \mathrm{LF}$ & $0.22 \pm 0.04$ & $1.00 \pm 0.06$ & $104 \pm 6$ & $2.6 \pm 0.5$ & $0.67 \pm 0.04$ \\
$6 \mathrm{~nm}-6 \mathrm{LF}$ & $0.50 \pm 0.05$ & $0.59 \pm 0.06$ & $96 \pm 9$ & $3.5 \pm 0.7$ & $4.1 \pm 0.4$ \\
Nanorods & $0.39 \pm 0.09$ & $0.13 \pm 0.04$ & $0.818 \pm 0.006$ & $0.037 \pm 0.003$ & $0.0598 \pm 0.0005$ \\
Microrods & $0.36 \pm 0.04$ & $0.18 \pm 0.07$ & $0.21 \pm 0.03$ & $0.040 \pm 0.006$ & $0.056 \pm 0.007$ \\
\hline \hline
\end{tabular}

is the reaction order with respect to the reactive surface sites. An example of the log-log graph used to determine $m$ for $4 \mathrm{~nm}-6 \mathrm{LF}$ is shown in Fig. 4(c), and an example of the log$\log$ graph used to determine $n$ for $4 \mathrm{~nm}-6 \mathrm{LF}$ is shown in Fig. 4(d). Reaction orders and rate constants for all particle types are presented in Table II, and all errors listed represent standard errors. Comparing the surface-area-normalized rate constants demonstrates that the ferrihydrite rate constants are up to two orders of magnitude larger than those for goethite. This is unsurprising since previous results have demonstrated that ferrihydrite is substantially more reactive than more crystalline iron oxides (i.e., goethite, hematite, etc.), and this was attributed to differences in crystallinity. ${ }^{7,92-31}$ Thus, 100 -fold greater reactivity observed for ferrihydrite versus goethite is most likely due to a combination of greater crystallinity and larger size of the goethite particles in comparison to the ferrihydrite particles.

The method of initial rates, which uses only the initial, linear portion of the data, provides for excellent, semiquantitative comparison between the goethite and ferrihydrite samples. However, it is not adequate for a quantitative comparison between the $4 \mathrm{~nm}-6 \mathrm{LF}$ and $6 \mathrm{~nm}-6 \mathrm{LF}$ ferrihydrite samples and the nanorod and microrod goethite samples. In order to refine the quantitative comparisons, the data were fit using one-dimensional (1D) diffusion kinetics for ferrihydrite and two-dimensional (2D) diffusion kinetics for goethite. These diffusion models are based on the idea that the kinetics are governed by the movement of the particles through the solution.

In the case of the spherical ferrihydrite particles, 1D diffusion kinetics yield the best fits since the particles essen-

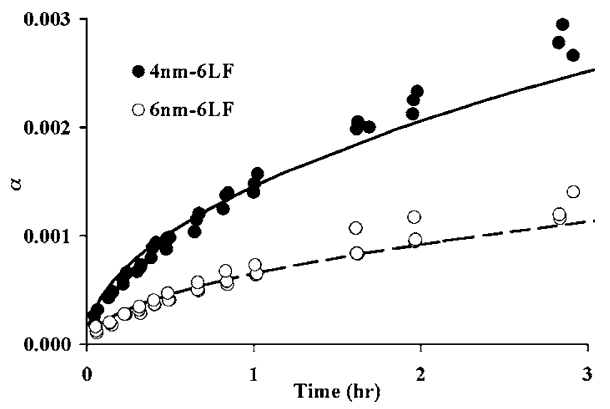

FIG. 5. Dissolution of ferrihydrite particles vs time. The fraction of solid dissolved, $\alpha$, was calculated from [Q] using the Q:Fe(II) stoichiometry. Experiments were performed in triplicate, and all data points are shown. Model curves for $1 \mathrm{D}$ diffusion kinetics were calculated by minimizing the unsigned mean error between the experimental data and the model. The solid curve is the best fit for the $4 \mathrm{~nm}-6 \mathrm{LF}$ data, and the dashed curve for the $6 \mathrm{~nm}-6 \mathrm{LF}$ data. tially act as spheres moving through the solution, and this is consistent with the approach used by Dold. ${ }^{51}$ Using Eq. (4), ${ }^{52}$ in which $r$ represents the 1D dissolution rate and $\alpha$ represents the fraction of solid dissolved at any given time, $t$, the data were fit by minimizing the unsigned mean error between the data and the model curve,

$$
\alpha^{2}=r t .
$$

An example is shown in Fig. 5 for 4 nm-6LF (closed circles) and $6 \mathrm{~nm}-6 \mathrm{LF}$ (open circles) using $0.1 \mathrm{mM} \mathrm{QH}_{2}$ and $2.0 \mathrm{~g} / \mathrm{L}$ particles with the model curves shown as solid and dashed lines. Since $r$ changes with $\left[\mathrm{QH}_{2}\right]$ and $[\mathrm{S}]$, the 1D rate constants and reaction orders with respect to both $\mathrm{QH}_{2}$ and reactive surface sites were determined using Eq. (3). After finding $r$ for each experiment, $m, n$, and $k$ were found using the above-described log-log graphing method. Reaction orders and rate constants for $4 \mathrm{~nm}-6 \mathrm{LF}$ and $6 \mathrm{~nm}-6 \mathrm{LF}$ are presented in Table III. Results clearly show that 1D, $\mathrm{SA}_{\mathrm{TEM}}$ normalized rate constants for the $4 \mathrm{~nm}-6 \mathrm{LF}$ nanoparticles are up to 16 times larger than for the $6 \mathrm{~nm}-6 \mathrm{LF}$ nanoparticles. This is a large difference, with the smaller particles exhibiting a substantially higher reactivity than the larger particles.

Alternative explanations for the reactivity difference include the presence of trace goethite in $4 \mathrm{~nm}-6 \mathrm{LF}$, the presence of carbonate in $4 \mathrm{~nm}-6 \mathrm{LF}$, and a possible difference in crystallinity between the $4 \mathrm{~nm}-6 \mathrm{LF}$ and $6 \mathrm{~nm}$-6LF samples. The presence of goethite in $4 \mathrm{~nm}$-6LF most likely means that the reactivity difference observed is a minimum estimate because goethite particles are dramatically less reactive than ferrihydrite particles (Table II). Next, $4 \mathrm{~nm}$-6LF particles were prepared using carbonate while $6 \mathrm{~nm}$-6LF particles were prepared without addition of carbonate (see methods, Secs. II A and II B). Preliminary results using similarly sized particles that were prepared with and without carbonate suggest a small decrease in reactivity with the inclusion of carbonate (reductive dissolution is only 1.3 times faster for the

TABLE III. Reaction orders for $\mathrm{QH}_{2}(m)$ and surface $(n)$ and rate constants (k) for each particle type using the 1D diffusion kinetic model. Errors reported are standard errors. $\mathrm{SA}_{\mathrm{TEM}}$ normalized rate constant is denoted by $k_{\mathrm{TEM}}$, and $\mathrm{SA}_{\mathrm{BET}}$ normalized rate constant is denoted by $k_{\mathrm{BET}}$.

\begin{tabular}{cccccc}
\hline \hline Particle ID & $m$ & $n$ & $k \times 10^{5}\left(\mathrm{~h}^{-1}\right)$ & $\begin{array}{c}k_{\mathrm{TEM}} \times 10^{8} \\
\left(\mathrm{~h}^{-1} \mathrm{~m}^{-2}\right)\end{array}$ & $\begin{array}{c}k_{\mathrm{BET}} \times 10^{8} \\
\left(\mathrm{~h}^{-1} \mathrm{~m}^{-2}\right)\end{array}$ \\
\hline $4 \mathrm{~nm}-6 \mathrm{LF}$ & $0.55 \pm 0.02$ & $0.51 \pm 0.06$ & $2.02 \pm 0.10$ & $4.9 \pm 0.9$ & $1.29 \pm 0.07$ \\
$6 \mathrm{~nm}-6 \mathrm{LF}$ & $0.79 \pm 0.10$ & $1.24 \pm 0.12$ & $0.082 \pm 0.010$ & $0.30 \pm 0.07$ & $0.35 \pm 0.04$
\end{tabular}




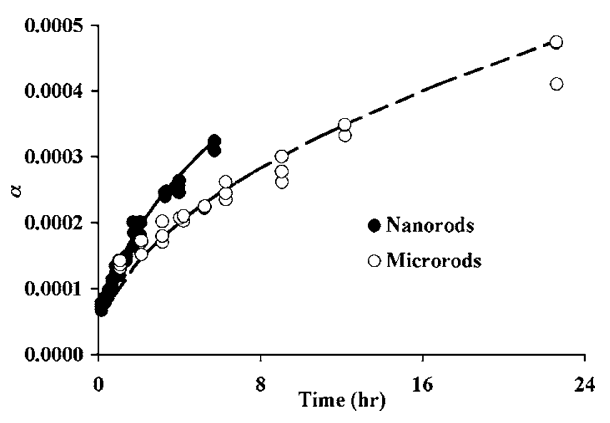

FIG. 6. Dissolution of goethite particles vs time. The fraction of solid dissolved, $\alpha$, was calculated from [Q] using the Q:Fe(II) stoichiometry. Experiments were performed in triplicate, and all data points are shown. Model curves for 2D diffusion kinetics were calculated by minimizing the unsigned mean error between the experimental data and the model. The solid curve is the best fit for the nanorod data, and the dashed for the microrod data.

carbonate-free particles). This suggests, again, that the reactivity difference observed is a minimum. Finally, it is possible that the reactivity difference is due to a crystallinity difference between the ferrihydrite samples. XRD patterns demonstrate that both ferrihydrites can be clearly classified as six-line ferrihydrite. However, the pattern for $6 \mathrm{~nm}-6 \mathrm{LF}$ exhibits narrower peaks than does the pattern for $4 \mathrm{~nm}-6 \mathrm{LF}$, which could be attributed to both a larger particle size and a higher degree of crystallinity. TEM results demonstrate a difference in particle size, which suggests that the primary difference between these two ferrihydrites is one of size. It is likely that surface energy varies as a function of size, ${ }^{2}$ and such an effect could be a consequence of the relative number of atoms at kinks versus facets and the relative number of atoms contained at or near the surface in comparison to the bulk. We conclude that the size-dependent reactivity observed here is a direct consequence of a difference in surface energy between these materials and that the surface energy of $4 \mathrm{~nm}-6 \mathrm{LF}$ is greater than that of $6 \mathrm{~nm}-6 \mathrm{LF}$. Finally, the difference in reaction orders is interesting. This result suggests that the mechanism by which the reductive dissolution occurs may change as a result of the synthetic procedure (i.e., the use of carbonate).

For the acicular goethite particles, 2D diffusion kinetics yield the best fits since the particles act as cylinders moving through the solution, and this is consistent with the approach used by Houben. ${ }^{29}$ Using Eq. (5), ${ }^{52}$ in which $r$ represents the 2D dissolution rate and $\alpha$ represents the fraction of solid dissolved at any given time, $t$, the data were fit by minimizing the unsigned mean error between the data and the model curve,

$$
(1-\alpha) \ln (1-\alpha)+\alpha=r t .
$$

An example is shown in Fig. 6 for nanorods (closed circles) and microrods (open circles) using $0.1 \mathrm{mM} \mathrm{QH}_{2}$ and $2.0 \mathrm{~g} / \mathrm{L}$ with the model curves shown as solid and dashed lines. Since $r$ changes with $\left[\mathrm{QH}_{2}\right]$ and $[\mathrm{S}]$, the $2 \mathrm{D}$ rate constants and reaction orders with respect to both $\mathrm{QH}_{2}$ and reactive surface sites were determined using Eq. (3), as described earlier. Reaction orders and rate constants for nanorods and microrods are presented in Table IV. Results clearly show that both the $\mathrm{SA}_{\mathrm{TEM}}$ and $\mathrm{SA}_{\mathrm{BET}}$ normalized, $2 \mathrm{D}$
TABLE IV. Reaction orders for $\mathrm{QH}_{2}(m)$ and surface $(n)$ and rate constants $(k)$ for each particle type using the $2 \mathrm{D}$ diffusion kinetic model. Errors reported are standard errors. $\mathrm{SA}_{\mathrm{TEM}}$ normalized rate constant is denoted by $k_{\mathrm{TEM}}$, and $\mathrm{SA}_{\mathrm{BET}}$ normalized rate constant is denoted by $k_{\mathrm{BET}}$.

\begin{tabular}{cccccc}
\hline \hline Particle ID & $m$ & $n$ & $\begin{array}{c}k \times 10^{8} \\
\left(\mathrm{~h}^{-1}\right)\end{array}$ & $\begin{array}{c}k_{\mathrm{TEM}} \times 10^{10} \\
\left(\mathrm{~h}^{-1} \mathrm{~m}^{-2}\right)\end{array}$ & $\begin{array}{c}k_{\mathrm{BET}} \times 10^{10} \\
\left(\mathrm{~h}^{-1} \mathrm{~m}^{-2}\right)\end{array}$ \\
\hline Nanorods & $0.92 \pm 0.12$ & $1.61 \pm 0.13$ & $9.9 \pm 1.2$ & $4.5^{\mathrm{a}} \pm 0.7$ & $7.2^{\mathrm{a}} \pm 0.9$ \\
Microrods & $0.82 \pm 0.18$ & $1.74 \pm 0.18$ & $1.38 \pm 0.16$ & $2.6^{\mathrm{a}} \pm 0.4$ & $3.6^{\mathrm{a}} \pm 0.4$ \\
\hline \hline
\end{tabular}

${ }^{\mathrm{a}}$ Note: Rate constants are 100-fold smaller than those shown in Table III.

rate constants for the nanorods are nearly two times larger than for the microrods, which is a significant but not large effect. The nanorods in this study have dimensions near the quantum refinement regime ${ }^{53}$ - that is, the smallest dimension ( $h$, in Fig. 1$)$ is approximately $4 \mathrm{~nm}$, on average. However, recent work has shown that quantum size effects are shape dependent and that these effects are weakened in rodshaped particles. ${ }^{53}$ Thus, we conclude that the overall size of the nanorods is likely near the maximum size at which such quantum size effects could be observed. While it is difficult to predict what effect the quantum refinement would have on the relative rates of reduction, that the minimum dimension is near the maximum size at which such quantum size effects could be observed suggests that the reactivity difference observed is not due to quantum refinement. A final consideration is defects, which are known to cause higher reactivity. ${ }^{54,55}$ Variations in contrast in TEM images, taken at multiple tilt conditions, demonstrate that the microrods have a much higher concentration of defects than the nanorods. Thus, we conclude that the twofold difference is an underestimate of the reactivity difference that would be expected solely as a result of size effects.

\section{CONCLUSIONS}

The relative reactivity of ferrihydrite and goethite nanoparticles has been quantified by measuring the rates of reductive dissolution of nanoparticles by hydroquinone. Results confirm that ferrihydrite is substantially more reactive than goethite and demonstrate that reactivity is size dependent in both goethite and ferrihydrite. While variations in synthesis methods, crystallinity, and/or presence of impurities may influence reactivity, our results show that these effects are small for this suite of samples. Experiments further exploring such effects are currently under way. Finally, these results highlight the need to develop synthetic methods that produce homogeneous and monodisperse goethite particles of a smaller size. To date, no method has been developed that can produce goethite nanoparticles in the $3-10 \mathrm{~nm}$ size range.

\section{ACKNOWLEDGMENTS}

A. J. A. and R. L. P. thank the University of Minnesota and the National Science Foundation (Divisions of Chemistry and Earth Sciences) for funding. We thank S. L. Brantley, J. L. Cantolina, and J.-H. Jang at Penn State University for assistance with BET and J. E. Kabrhel for assistance with NMR. 
${ }^{1}$ A. Navrotsky, in Nanoparticles and the Environment, edited by J. F. Banfield and A. Navrotsky (Mineralogical Society of America, Washington, DC, 2001), Vol. 44, pp. 73-104.

${ }^{2}$ J. F. Banfield and H. Zhang, in Ref. 1, 44, pp. 1-58.

${ }^{3}$ R. M. Cornell and U. Schwertmann, The Iron Oxides: Structure, Properties, Reactions, Occurrences, and Uses, 2nd, completely rev. and extended ed. (Wiley-VCH, Weinheim, 2003).

${ }^{4}$ K. H. Nealson and D. A. Stahl, in Geomicrobiology: Interactions Between Microbes and Minerals, edited by J. F. Banfield and K. H. Nealson (The Mineralogical Society of America, Washington, DC, 1997), Vol. 35, pp. 5-34.

${ }^{5}$ D. Fortin, F. G. Ferris, and T. J. Beveridge, in Ref. 4, Vol. 35, pp. 161-180

${ }^{6}$ G. E. Brown, Jr., V. E. Henrich, W. H. Casey, D. L. Clark, C. Eggleston, A. Felmy, D. W. Goodman, M. Gratzel, G. Maciel, M. I. McCarthy, K. H. Nealson, D. A. Sverjensky, M. F. Toney, and J. M. Zachara, Chem. Rev. (Washington, D.C.) 99, 77 (1999).

${ }^{7}$ E. E. Roden, Geochim. Cosmochim. Acta 68, 3205 (2004).

${ }^{8}$ W. D. Burgos, Y. Fang, R. A. Royer, G.-T. Yeh, J. J. Stone, B.-H. Jeon, and B. A. Dempsey, Geochim. Cosmochim. Acta 67, 2735 (2003).

${ }^{9}$ E. E. Roden, Environ. Sci. Technol. 37, 1319 (2003).

${ }^{10}$ R. A. Royer, W. D. Burgos, A. S. Fisher, R. F. Unz, and B. A. Dempsey, Environ. Sci. Technol. 36, 1939 (2002).

${ }^{11}$ J. K. Fredrickson, J. M. Zachara, D. W. Kennedy, H. Dong, T. C. Onstott, N. W. Hinman, and S.-M. Li, Geochim. Cosmochim. Acta 62, 3239 (1998).

${ }^{12}$ C. Liu, S. Kota, J. M. Zachara, J. K. Fredrickson, and C. K. Brinkman, Environ. Sci. Technol. 35, 2482 (2001).

${ }^{13}$ E. E. Roden and J. M. Zachara, Environ. Sci. Technol. 30, 1618 (1996).

${ }^{14}$ J. M. Zachara, J. K. Fredrickson, S.-M. Li, D. W. Kennedy, S. C. Smith, and P. L. Gassman, Am. Mineral. 83, 1426 (1998).

${ }^{15}$ J. M. Zachara, J. K. Fredrickson, S. C. Smith, and P. L. Gassman, Geochim. Cosmochim. Acta 65, 75 (2001).

${ }^{16}$ J. F. Banfield and R. J. Hamers, in Ref. 4, Vol. 35, pp. 81-122.

${ }^{17}$ S. Wang and W. A. Arnold, Water Res. 37, 4191 (2003).

${ }^{18}$ R. G. Ford, P. M. Bertsch, and K. J. Farley, Environ. Sci. Technol. 31, 2028 (1997).

${ }^{19}$ R. G. Ford, Environ. Sci. Technol. 36, 2459 (2002).

${ }^{20}$ I. Meusel, J. Hoffmann, J. Hartmann, J. Libuda, and H.-J. Freund, J. Phys. Chem. B 105, 3567 (2001).

${ }^{21}$ R. K. Sharma, P. Sharma, and A. Maitra, J. Colloid Interface Sci. 265, 134 (2003).

${ }^{22}$ S. Park, Y. Xie, and M. J. Weaver, Langmuir 18, 5792 (2002).

${ }^{23}$ J. Hagen, L. D. Socaciu, U. Heiz, T. M. Bernhardt, and L. Woste, Eur. Phys. J. D 24, 327 (2003).

${ }^{24}$ W. T. Wallace and R. L. Whetten, J. Phys. Chem. B 104, 10964 (2000).

${ }^{25}$ E. W. Brennan and W. L. Lindsay, Soil Sci. Soc. Am. J. 62, 930 (1998)

${ }^{26}$ E. Gonzalez, M. C. Ballesteros, and E. H. Rueda, Clays Clay Miner. 50, 470 (2002).
${ }^{27}$ J. Torrent, U. Schwertmann, and V. Barron, Clay Miner. 22, 329 (1987)

${ }^{28}$ K.-H. Kung and M. B. McBride, Clays Clay Miner. 36, 303 (1988).

${ }^{29}$ G. J. Houben, Appl. Geochem. 18, 941 (2003).

${ }^{30}$ D. Postma, Geochim. Cosmochim. Acta 57, 5027 (1993).

${ }^{31}$ O. Larsen and D. Postma, Geochim. Cosmochim. Acta 65, 1367 (2001).

${ }^{32}$ D. K. Newman and R. Kolter, Nature (London) 405, 94 (2000).

${ }^{33}$ D. T. Scott, D. M. McKnight, E. L. Blunt-Harris, S. E. Kolesar, and D. R. Lovley, Environ. Sci. Technol. 32, 2984 (1998).

${ }^{34}$ D. R. Lovley, J. L. Fraga, E. L. Blunt-Harris, L. A. Hayes, E. J. P. Phillips, and J. D. Coates, Acta Hydrochim. Hydrobiol. 26, 152 (1998).

${ }^{35}$ S. E. Childers, S. Clufo, and D. R. Lovley, Nature (London) 416, 767 (2002).

${ }^{36}$ K. P. Nevin and D. R. Lovley, Appl. Environ. Microbiol. 68, 2294 (2002).

${ }^{37}$ The Surface Chemistry of Soils, edited by G. Sposito (Oxford University Press, Oxford, 1984).

${ }^{38}$ D. L. Norwood, J. D. Johnson, R. F. Christmann, J. R. Hass, and M. J. Bobenrieth, Environ. Sci. Technol. 14, 187 (1980).

${ }^{39}$ A. G. Stack, C. M. Eggleston, and M. H. Engelhard, J. Colloid Interface Sci. 274, 433 (2004).

${ }^{40}$ A. G. Stack, K. M. Rosso, D. M. A. Smith, and C. M. Eggleston, J. Colloid Interface Sci. 274, 442 (2004).

${ }^{41}$ J. S. LaKind and A. T. Stone, Geochim. Cosmochim. Acta 53, 961 (1989).

${ }^{42}$ J. Pracht, J. Boenigk, M. Isenbeck-Schroter, F. Keppler, and H. F. Scholer, Chemosphere 44, 613 (2001).

${ }^{43}$ D. J. Burleson and R. L. Penn, Langmuir (submitted).

${ }^{44} \mathrm{U}$. Schwertmann and R. M. Cornell, Iron Oxides in the Laboratory: Preparation and Characterization, 2nd completely revised and extended ed. (Wiley-VCH, Weinheim, 2000).

${ }^{45}$ L. L. Stookey, Anal. Chem. 42, 779 (1970).

${ }^{46}$ S. Brunauer, P. H. Emmett, and E. Teller, J. Am. Chem. Soc. 60, 309 (1938).

${ }^{47}$ K. S. W. Sing, D. H. Everett, R. A. W. Haul, L. Moscou, R. A. Pierotti, J. Rouquerol, and T. Siemieniewska, Pure Appl. Chem. 57, 603 (1985).

${ }^{48}$ P. Scherrer, Nachr. Ges. Wiss. Goettingen, Math.-Phys. Kl. 26, 98 (1918).

${ }^{49}$ B.-H. Jeon, B. A. Dempsey, and W. D. Burgos, Environ. Sci. Technol. 37, 3309 (2003).

${ }^{50}$ E. S. Swinbourne, Analysis of Kinetic Data, edited by W. C. Agosta and R. S. Nyholm (Nelson, London, 1971).

${ }^{51}$ B. Dold, Appl. Geochem. 18, 1531 (2003).

${ }^{52}$ C. H. Bamford and C. F. H. Tipper, Comprehensive Chemical Kinetics, Vol. 22 of Reactions in the Solid State (Bamford and Tipper, Amsterdam, 1980).

${ }^{53}$ H. Yu, J. Li, R. A. Loomis, L.-W. Wang, and W. E. Buhro, Nat. Mater. 2, 517 (2003).

${ }^{54}$ R. L. Penn, A. T. Stone, and D. R. Veblen, J. Phys. Chem. B 105, 4690 (2001).

${ }^{55}$ J. F. Banfield, G. G. Ferruzzi, W. H. Casey, and H. R. Westrich, Geochim. Cosmochim. Acta 59, 19 (1995). 